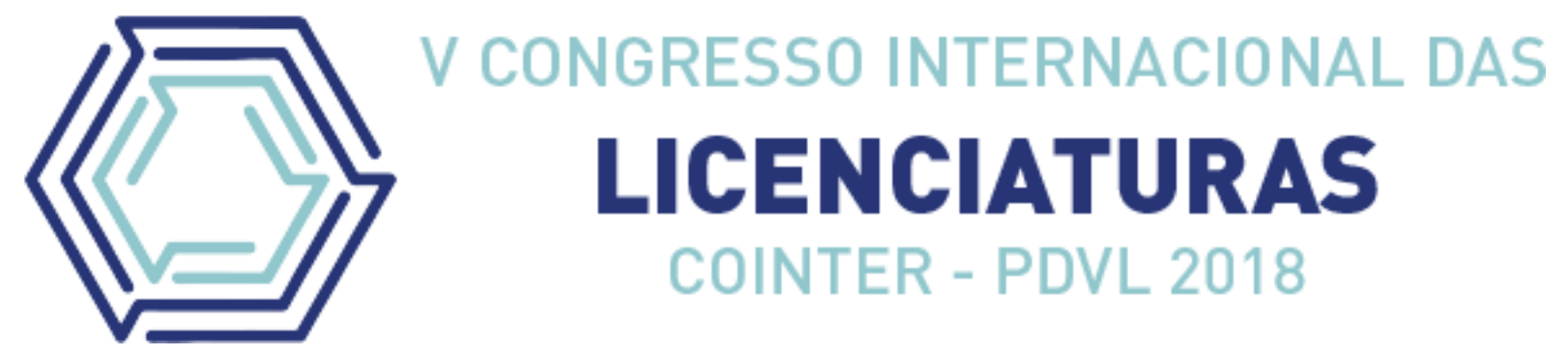

\title{
QUIMICA EM TOM: UTILIZAÇÃO DE PARÓDIAS COMO ESTRATÉGIA DE ENSINO E APRENDIZAGEM NA QUÍMICA
}

\section{CHEMISTRY IN TONE: USE OF PARODIES AS A STRATEGY FOR TEACHING AND LEARNING IN CHEMISTRY}

\author{
Apresentação: Comunicação Oral \\ Rita de Cássia Silva Di Pace ${ }^{1}$; Diego Gomes de Sousa ${ }^{2}$; Elaine da Silva Vasconcelos ${ }^{3}$ \\ DOI: $\underline{\text { https://doi.org/10.31692/2358-9728.VCOINTERPDVL.2018.00140 }}$
}

\section{Resumo}

O uso de recursos didáticos diversificados é uma tentativa de superar o desinteresse pela disciplina de Química, pois grande parte dos alunos considera tal disciplina como de difícil compreensão, pelo fato de conter cálculos, fórmulas, regras e, consequentemente, acabam criando obstáculos e uma ideia de que essa Ciência é algo abstrato, cansativo e complexo, o que acarreta a falta de integração no cotidiano desses discentes. Uma alternativa promissora é o uso da linguagem musical na educação científica. Tal processo educativo conduzido pelo uso desse recurso pode proporcionar aulas mais dinâmicas e motivadoras, capazes de transmitir conhecimentos científicos, como também desenvolver habilidades para a produção textual e comunicação, além de auxiliar o aluno a pensar criticamente. É importante ressaltar que, a música tem uma presença significativa na vida do aluno, podendo auxiliar no aprendizado científico. Portanto, o presente estudo tem como objetivo demonstrar uma ferramenta didática diferenciada, o uso de paródias com músicas do cotidiano dos alunos, no intuito de facilitar o processo de ensino e aprendizagem sobre o seguinte conteúdo: estrutura atômica. Este estudo foi desenvolvido e aplicado em uma turma do $1^{\circ}$ ano do Ensino Médio, de uma escola estadual (IEP) parceira do programa PDVL Química Campus João Pessoa, no estado da Paraíba. Este trabalho foi baseado no método qualitativo e os resultados foram bastante construtivos, com uma boa repercussão na escola perante os docentes e com

\footnotetext{
${ }^{1}$ Licenciatura em Química, IFPB, diegogomees28@gmail.com

${ }^{2}$ Licenciatura em Química, IFPB, rita.pace@academico.ifpb.edu.br

${ }^{3}$ Doutoranda em Química, IFPB, elainesvquimica@hotmail.com
} 
uma participação intensa dos alunos, com muita descontração e alegria durante a aplicação da atividade, a qual apresentou uma ótima eficácia na assimilação do conteúdo químico associado à linguagem musical.

Palavras-Chave: ensino de química, música, paródia.

\begin{abstract}
The use of diversified didactic resources is an attempt to overcome disinterest in the discipline of Chemistry, since most students consider this discipline as difficult to understand, because it contains calculations, formulas, rules and, consequently, automatically create an obstacle and an idea that this Science is something abstract, tiring and complex, which entails the lack of integration in the daily life of these students. A promising alternative is the use of musical language in scientific education. Such an educational process driven by the use of this resource can provide more dynamic and motivating lessons capable of transmitting scientific knowledge, as well as developing skills for textual production and communication, as well as helping the student to think critically. It is important to emphasize that music has a significant presence in the life of the student, and can aid in the scientific learning. Therefore, the present study aims to demonstrate a differentiated didactic tool, the use of parodies with students' daily songs, in order to facilitate the process of teaching and learning about the following content: atomic structure. This study was developed and applied in a 1st year high school class of a state school (IEP) partner of the program PDVL Química Campus João Pessoa, in the state of Paraíba. This work was based on the qualitative method and the results were very constructive, with a good repercussion in the school before the teachers and with an intense participation of the students, with much relaxation and joy during the application of the activity, which presented a great efficiency in the assimilation of the chemical content associated with the musical language.
\end{abstract}

Keywords: chemistry teaching, interdisciplinarity, music, parody.

\title{
Introdução
}

$\mathrm{Na}$ atual conjuntura, é perceptível constatar que o livro didático é o material mais presente nas salas de aulas brasileiras. Tal instrumento auxilia o professor de várias formas, permitindo-o fazer buscas, esclarecer dúvidas, planejar aulas e até mesmo utilizar e realizar os exercícios propostos no livro com seus alunos. O uso não moderado desse recurso didático, pode acarretar em uma certa rotina em sala, a qual deixa os alunos desmotivados e continuamente no lugar de expectador passivo, limitando as possibilidades de aprendizagem. Dentro desse contexto, evidenciando (Silveira e Kiouranis, 2008, p.28), "não devemos esquecer que os alunos, em todos os níveis de aprendizagem, estão imersos em novas 
tecnologias e novas linguagens, decorrente da ampla e irrestrita difusão de informações”. De acordo com Wermann,

O ensino diversificado é geralmente desvalorizado devido ao fato de o professor ter como principal barreira o excesso de conteúdo, perdendo-se assim o foco da aprendizagem da forma com que ela se constrói e se consolida na vida do aluno, desenvolvendo valores, habilidades e atitudes. Surge à necessidade de valorizar o processo de ensino aprendizagem, despertar no aluno atitudes e valores que o possibilite se desenvolver como cidadão. A criação de atividades diferenciadas voltadas para a construção do conhecimento e para a valorização do aluno como ser humano torna a aprendizagem algo fácil, divertido e vantajoso de ser desenvolvido. (WERMANN, 2011, p.1.)

Diante disso, o professor, enquanto mediador do conhecimento, precisa abster-se da metodologia de ensino obsoleta e se adequar com o contexto atual, utilizando novos materiais e estratégias de ensino para que se tenha uma melhor compreensão nos conteúdos químicos. Nesse sentindo, fazer uso da linguagem musical como ferramenta para o desenvolvimento do ensino aprendizagem é de extrema importância, tendo em vista que a música estreita laços entre alunos, professores e o conhecimento científico ao abordar temáticas com grande potencial de problematização presentes de forma significativa na vida do aluno.

A música faz parte do dia-a-dia de todos, principalmente entre as crianças e os adolescentes. Hoje a facilidade de acesso à celular, computadores, aparelhos que executam músicas é enorme e eles podem ser utilizados na escola como ferramentas do conhecimento e mediar as relações vividas nesse ambiente. Através da música conseguimos comunicar sentimentos e pensamentos através de organizações harmônicas de sons e silêncio. Não existe ser que não tenha vivido alguma experiência, seja ela boa ou ruim, e não tenha associado a uma música, pois toda pessoa tem preferências de gêneros musicais diferentes, independentemente da idade. Cuervo (2011) considera a música como uma arte que se utiliza da linguagem para a comunicação e expressão, dessa forma ela possui semelhança com a língua falada, mas que envolve diferentes entonações, ritmos, andamentos e contornos melódicos.

As atividades envolvendo músicas nas escolas, devem aproveitar o que o aluno conhece, se desenvolvendo dentro das condições de cada um de acordo com a sua limitação. A paródia é uma delas, que permite a modificação da letra original de uma música preservando sua melodia, ferramenta muito usada em campanhas eleitorais, propagandas em 
geral etc. Devido à dificuldade dos alunos em assimilar conteúdos referentes à disciplina de química, reflexo de uma prática metodológica tradicional, a qual é marcada pelo processo de ensino/aprendizagem mecânico, acaba ocasionando um certo desinteresse no alunado, que por sua vez provoca um baixo rendimento escolar. Segundo (Boschi, 1999, p. 189), “[...], mas não é em escolas no modelo arcaico que se aprenderá a transgredir. Há que ser em escolas que tenham a arte em primeiro plano: teatro, artes plásticas, literatura, música, etc.”. Então, faz-se necessário uma maior dinamização na construção do conhecimento.

Nesse contexto, o presente artigo relata uma das ações realizadas através do projeto de extensão e pesquisa intitulado de "Química em Tom”. Tendo como objetivo, avaliar a paródia como uma estratégia de ensino na aprendizagem conceitual referente ao conteúdo de química (Estrutura Atômica), conteúdo base de grande importância para a ciência em estudo, sendo possível esclarecer diante de várias teorias, do que seria constituída a matéria, a qual nós conhecemos hoje por átomos. Logo, a elaboração desse gênero textual como uma ferramenta interdisciplinar, atua como uma alternativa a mais para que o docente auxilie o aluno no desenvolvimento do conteúdo abordado em sala, contribuindo de forma eficaz e dinâmica para a construção do conhecimento.

\section{Fundamentação Teórica}

Os alunos geralmente falham na compreensão e reconhecimento das atividades e avaliações escolares, pois não conseguem relacionar a aprendizagem à uma valorização na sua vida. A motivação tornou-se um problema na educação e, dessa forma, os professores além de motivadores, devem ser facilitadores de autonomia de seus alunos, capazes também de fortalecer as necessidades psicológicas básicas de autodeterminação, de competência e de segurança.

A disciplina de química está vinculada a escola, tendo como principal objetivo ensinar ao aluno "o funcionamento do mundo natural e a planejar, executar e avaliar ações de intervenção na realidade natural” (BRASIL, 2000). Entretanto, nessa ciência, a metodologia tradicional não é atrativa, pois os docentes não utilizam técnicas e outro recurso para tornar o ensino mais atraente e eficiente, o que acarreta em um processo mais difícil e complexo. A utilização de novos materiais e estratégias de ensino, apesar de amplamente disseminada, não 
é ainda, amplamente praticada, especialmente em escolas públicas. Torna-se indispensável, no atual cenário, que as aulas sejam dinamizadas a partir de diferentes ferramentas pedagógicas, visto que a série de informações e as possibilidades de interações pessoais já são altamente dinâmicas.

Vale ressaltar, que as aulas expositivas exercem sua importância no processo de ensino e aprendizagem e as ferramentas didáticas diferenciadas como a paródia, não substitui essas aulas, pois essas são primordiais. Contudo, o uso de tal metodologia ajuda também na melhora disciplinar quando usado como um recurso auxiliar da aprendizagem, contribuindo para a ampliação dos conteúdos químicos e de outras disciplinas, uma vez que ele aumenta a sensibilidade e a criatividade em se fazer relações entre o contexto da música refletido na letra que a compõe e o conhecimento científico. Segundo os estudos de Silveira e Kiouranis (2008), a música como abordagem do conhecimento químico é pouco incorporada nas estratégias de ensino empregadas nas escolas, entretanto, ela se revela extremamente útil quando empregada no ensino desta ciência, pois envolve a emoção e a afetividade, desperta a motivação e o interesse e favorece a coletividade no convívio de sala de aula.

Segundo a lei brasileira sobre direitos autorais, Lei 9.610/98 Art. 47. são livres as paráfrases e paródias que não forem verdadeiras reproduções da obra originária nem lhe implicarem descrédito (BETTIO, 2010). Nesse sentido, a paródia sempre será uma possibilidade de ensino, visto que, o professor é hábil para a construção, pois, possui o conhecimento da área de domínio e das estratégias pedagógicas. Segundo definição do dicionário da língua portuguesa, a paródia pode ser definida como: "Obra literária, teatral, musical etc. que imita outra obra, ou os procedimentos de uma corrente artística, escolar etc. com objetivo jocoso ou satírico; arremedo" (HOUAISS, 2009, p. 1437).

Contudo, Silva (2014) alerta para o fato do trabalho com música em sala de aula não se tornar um acessório para entretenimento quando as aulas se tornarem fastidiosas e desmotivadoras. Ele ainda defende que a música é uma atividade lúdica que transpõe a barreira da educação formal e pode ser utilizada, inclusive, como atividade cultural (p. 23).

Uma forma diferente e dinâmica de trabalhar os conteúdos é a paródia, vez que [...] ao longo da existência do ser humano, a prática de associar qualquer disciplina à música sempre foi bastante utilizada e demonstrou muitas potencialidades como fator auxiliar no aprendizado, podendo ainda despertar e 
desenvolver nos alunos sensibilidades mais aguçadas na observação de questões próprias à disciplina alvo, além de melhorar a qualidade do ensino e aprendizado, uma vez que estimula e motiva professores e alunos. (MELO; ASSIS, s/d, p.4.).

Diante desse fato, justifica-se o uso de paródias como estratégias de ensino e aprendizagem, uma vez que não somente despertou o interesse de autoria e elaboração de um "novo produto", como também permitiu aos alunos a aquisição de conhecimentos novos, possibilitando aos educandos a compreensão de conceitos básicos fundamentais para a compreensão do conteúdo de estrutura atômica.

\section{Metodologia}

A pesquisa foi desenvolvida por uma discente bolsista e outro voluntário que faz parte do projeto pertencente ao PDVL (Programa Despertando Vocações para as Licenciaturas) Química acompanhado da professora regente da turma do $1^{\circ}$ Ano $\mathrm{MB}$ do nível médio de ensino, do Instituto Educacional da Paraíba, localizado na cidade de João Pessoa - Paraíba. Foram necessárias 4 (quatro) aulas para aplicação das práxis, contendo 45 (quarente e cinco) minutos cada aula com trinta (30) estudantes participantes. Para tal, foram aplicados além da paródia, um Questionário Inicial (QI), uma Aula de Revisão (AR), e um Questionário Final $(\mathrm{QF})$, contendo 5 (cinco) questões cada.

O estudo foi desenvolvido com base em uma pesquisa qualitativa, incentivando a interação aluno-professor, norteando o rumo da pesquisa, na qual uma abordagem qualitativa "trabalha com valores, crenças, representações, hábitos, atitudes e opiniões. Ela aprofunda a complexidade de fenômenos, fatos e processos; passa pelo observável e vai além dele ao estabelecer inferências e atribuir significados ao comportamento" (SILVA, 2010, p. 6).

O procedimento da pesquisa está elencado na seguinte ordem: nas duas primeiras aulas foram apresentadas as propostas do projeto, explanando os objetivos e o que se propunha com o desenvolvimento do mesmo e, ainda, foi entregue um Termo de Consentimento Livre e Esclarecido (TCLE), para que os discentes que desejassem participar pudessem coletar a assinatura do responsável, já que são menores de idade. Por último, foi realizada a aplicação do Questionário Inicial (QI) e da Aula de Revisão (AR). O questionário tinha por objetivo sondar as dificuldades enfrentadas pelos alunos ao estudar o conteúdo de estrutura atômica, em seguida, tais levantamentos das questões discutidas em sala, serviram de apoio para a produção e a inserção da paródia focando na problemática exposta, que 
discorria sobre dúvidas como: do que era feito um átomo; quais eram os modelos atômicos; qual a relação da atomicidade com a tabela periódica.

Na terceira e quarta aula, segundo e último momento, desenvolveu-se a aplicação da paródia "Show dos Átomos" utilizando-se apenas um instrumento musical: o violão, e depois aplicou-se o Questionário Final (QF), no intuito de avaliar a aprendizagem dos discentes. Tal questionário, de cunho direto, foi elaborado com cinco (5) questões, tomando como base o desenvolvimento da turma no QI. Previamente, realizou-se a apresentação da paródia com a discente bolsista do PDVL, para que os alunos compreendessem a letra em conjunto com a melodia e pudessem cantar de forma correta posteriormente.

\section{Resultados e Discussão}

Nas duas primeiras aulas, inicialmente, foi realizado o Questionário Inicial (QI) e logo após a Aula de Revisão (AR), afim de relembrar alguns conceitos com a turma. O questionário continha cinco (5) questões. Os resultados desse seguem descritos. O primeiro questionamento discorreu em: “O que são partículas subatômicas?". Grande parte dos trinta (30) alunos presentes responderam que não sabiam quais eram e nem suas respectivas cargas. Tal questionamento teve o intuito de identificar o conhecimento prévio do alunado, para averiguar a capacidade deles de construir alternativas para responder à pergunta.

O segundo questionamento proferiu em: "Vocês acham importante que o professor faça uso de outras ferramentas de ensino? ". Diante de tal questão surgiu várias respostas como: "Ia ser muito bom ter aulas diferentes porque é muito chato só livro" e também "Sim, seria bom ver outras coisas e aprender sem ser olhando pra quadro”. Nas duas últimas aulas, segundo momento, foi realizado a leitura da letra da paródia em conjunto com os alunos e a professora regente, com o intuito de associar e compreender os conceitos químicos abordados na letra, antes da realização do canto como mostra a Figura 1. 


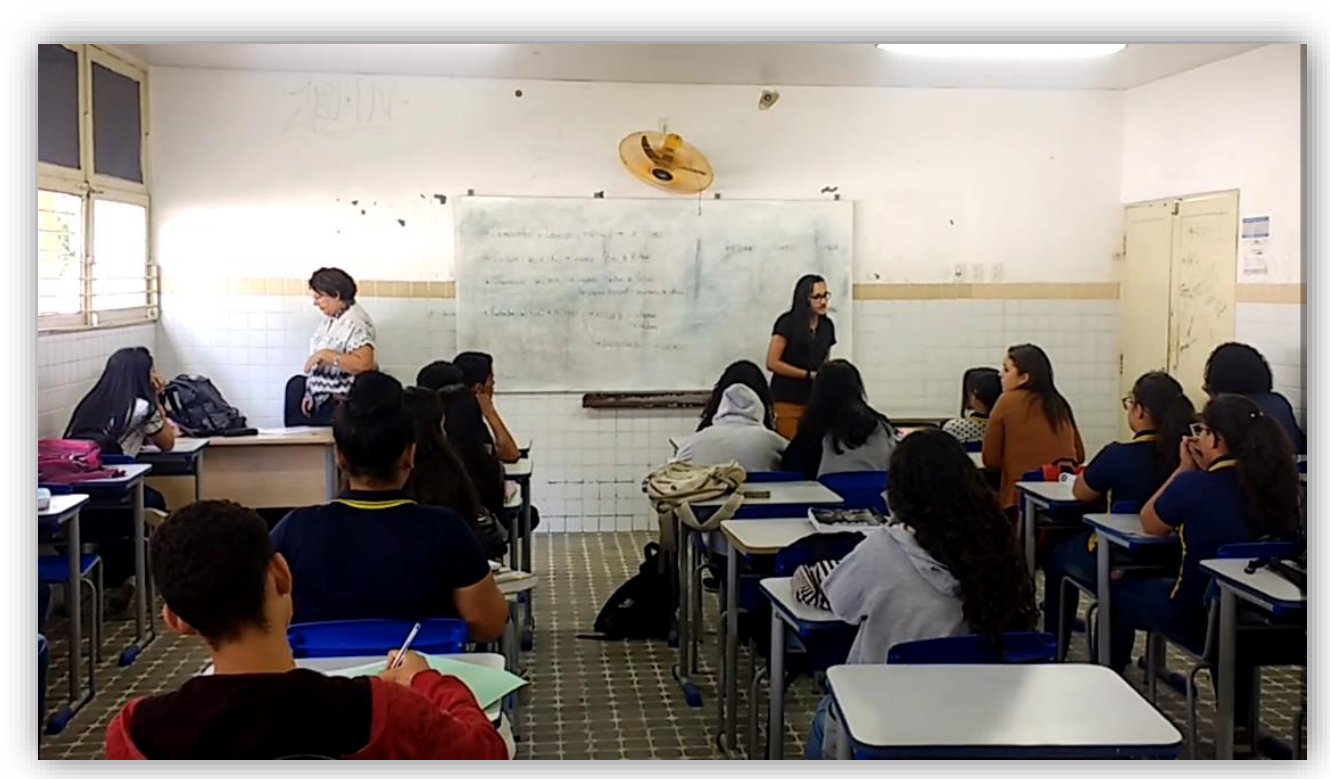

Na sequência, será ilustrado como foi construída a letra da paródia supramencionada a partir da letra original:

Tabela 1: Letra da paródia sobre Estrutura Atômica (lado direito) desenvolvida com base na música original (lado esquerdo). Fonte: própria.

\begin{tabular}{|c|c|}
\hline Anitta - "Show das Poderosas" (canção & Show dos Átomos (Paródia) \\
original) & \\
\hline Prepara, que agora é a hora & \\
Do show das poderosas \\
Que descem e rebolam & Prepara, que agora é hora \\
Afrontam as fogosas & De estudar o átomo \\
Que só é formado \\
Só as que incomodam & Por pequenas partículas \\
Expulsam as invejosas & Então vamos lá \\
Que ficam de cara quando toca & Entender sua estrutura \\
& Que é dividida em duas partes: \\
Se não tá mais à vontade, sai por onde entrei & Na eletrosfera temos apenas elétrons \\
Quando começo a dançar, te enlouqueço, eu sei & No núcleo temos prótons, nêutrons, eu sei \\
Meu exército é pesado, e a gente tem poder & Oétron (-), próton (+) e nêutron nulo \\
Ameaça coisas do tipo: Você! & Vai formar o átomo e você vai ver! \\
Solta o som que é pra me ver, dançando & O elétron (-) gira ao redor, do núcleo \\
Até você vai ficar, babando & Que tem carga igual o próton: positivo \\
Para o baile pra me ver dançando & E na tabela periódica: \\
Chama atenção à toa & Número atômico é Z \\
Perde a linha, fica louca & E o de massa é A \\
& \\
\hline
\end{tabular}


Dando prosseguimento a aplicação, foi feita a apresentação da paródia com a participação de todos os alunos presentes com o auxílio de um violão, tocado por um membro bolsista da equipe PDVL, como demonstra a Figura 2.

Figura 2: Momento do canto da paródia com auxílio de um violão conduzido por um membro da equipe PDVL. Fonte: Própria

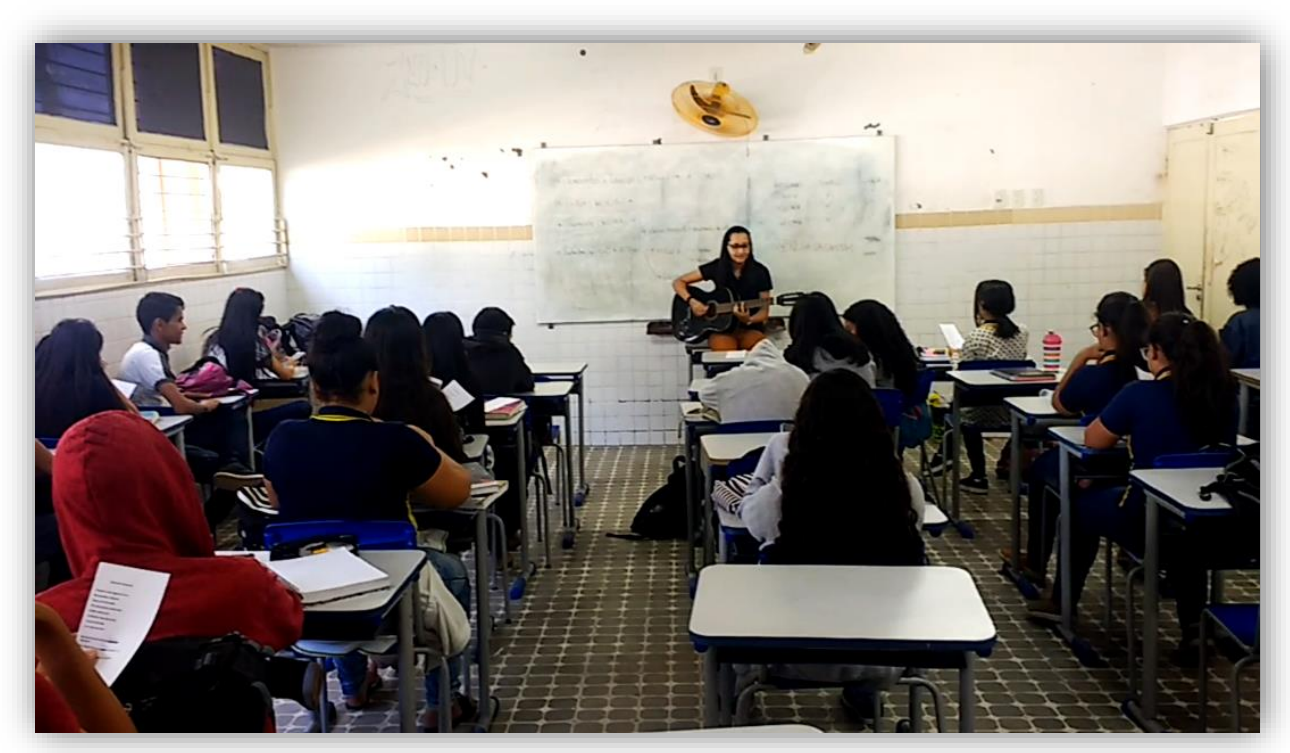

Após a paródia, um Questionário Final (QF) foi elaborado com base no QI contendo um total de 5 (cinco) questões, buscando avaliar o conhecimento adquirido pelos discentes após o desenvolvimento das ações. Duas delas eram referentes à paródia desenvolvida em sala de aula, que discorria: "A respeito da paródia, você acha que fazendo o uso dessa linguagem musical, os conteúdos químicos seriam mais fáceis de compreender?;"De acordo com a paródia apresentada, quem faz parte da eletrosfera e qual sua carga? ". Um dos alunos respondeu o primeiro questionamento: "Sim, é um jeito mais divertido de aprender, queria que os outros professores fizessem isso, ia ajudar muito.”. A grande maioria dos alunos responderam o segundo questionamento: "Elétrons, carga negativa". A outra pergunta investigava se os discentes conseguiam identificar do que consistia o átomo através da paródia apresentada em sala, e foi pedido que eles respondessem, cantando a estrofe da música que continha tal informação.

Frente à análise das respostas, foi possível constatar que todos os estudantes conseguiram responder corretamente e assimilar o conteúdo, atribuindo um resultado positivo, já que no Questionário Inicial não souberam responder a maioria dos questionamentos. Dentro 
dessa perspectiva, pode-se afirmar que este conjunto de ações aplicado pela equipe pesquisadora do projeto auxiliou de maneira eficaz o desenvolvimento cognitivo dos alunos em relação ao conteúdo estudado.

\section{Conclusões}

A realização desta aula contextualizada, apresentou vários benefícios no processo educativo, principalmente quanto ao trabalho coletivo, melhorando a relação pessoal entre os alunos, assim como em relação à aprendizagem. As atividades desenvolvidas nos remetem à conclusão de que a música como abordagem de conhecimento químico, dificilmente é incorporada nas estratégias de ensino mais recomendadas, contudo, entendemos que ela se revela absolutamente útil na interpretação de mensagens do cotidiano que têm significado social, científico e tecnológico. Esperamos que o discente, ao passar por uma experiência como essa nas aulas, possa englobar a ciência como uma parte integrante de sua cultura geral e, no caso particular da Química, perceber que ela pode superar a simples memorização de fórmulas. De forma espontânea, a música associada ao conteúdo químico desenvolvido neste trabalho, foi assimilada de maneira auspiciosa, obtendo um resultado significativo que despertou o interesse não só dos alunos, como também da professora regente. É interessante ressaltar, também, que a demonstração de tais dados expressivos foi de suma importância para a formação de toda a equipe presente neste trabalho, promovendo também em nós, que estamos no processo de formação à docência, uma motivação e estimulo para seguir com tal profissão.

Dentro desse contexto, a equipe pesquisadora do projeto que faz parte do Programa Despertando Vocações para as Licenciaturas (PDVL) pretende continuar a pesquisa abordando diferentes conteúdos de Química, utilizando essa proposta didática que executa uma metodologia contemporânea e diferenciada, a fim de contribuir com o processo de ensino/aprendizagem dos estudantes e despertar o interesse deles por essa Ciência. 


\section{Referências}

BETTIO, Maíra Althoff De, Paródia. [S.1.:s.n]. [2010]. Disponível em: <http:www.inforescola.com/gêneros-literarios/parodia>. Acesso em: 15 Set 2017.

BOSCHI, Ronaldo. O jogo teatral da cultura pós-moderna. 1999. 268f. Dissertação (Mestrado) - Pontifícia Universidade Católica de Minas Gerais, Programa de Pós-Graduação em Letras.

BRASIL. Orientações curriculares para o ensino médio: Secretaria de Educação Básica. Brasília: MEC. v. 2. , 2006.

CUERVO, L. Educação musical e a ideia de arquiteturas pedagógicas: práticas na formação de professores da geração "nativos digitais". Revista da ABEM, v.20, n.29, p.62-77, 2012.

HOUAISS, Antônio; VILLAR, Mauro de Salles; FRANCO, Francisco Manuel de Mello. Dicionário da língua portuguesa. 1. ed., Rio de Janeiro: Editora Objetiva, 2009.

MELO, T; ASSIS, M. Paródia Musical Como Ferramenta na Educação Ambiental Escolar. Programa Institucional de Bolsa de Iniciação à Docência. PPGECM/UEPB. Disponível em: <http://www.editorarealize.com.br/revistas/eniduepb/trabalhos/Modalidade_6datahora_04_10 _2013_11_40_57_idinscrito_641_f471c7534abf65bbf80b18bdfd226bf9.pdf>. Acesso em: 29 set 2018.

SILVA, C. M.; MERTINS, S.; SAMRSLA, V. E. E. Estratégias para o Ensino de Química: a utilização de paródias para tornar o aprendizado significativo. Rio Grande do Sul: Universidade de Santa Cruz do Sul- Unisc, 2014. p. 36-37. Disponível em: $<$ http://online.unisc.br/acadnet/anais/index.php/edeq/article/viewFile/11903/1752>. Acesso em 10 set 2018.

SILVA, G. C. R. F. O Método Científico na Psicologia: Abordagem qualitativa e quantitativa, 2010. Disponível em: <http://www.psicologia.pt/artigos/textos/A0539.pdf>. Acesso em: 29 set 2018.

SILVEIRA, M. P.; KIOURANIS, N. M. M. A música e o ensino de química. Química nova na escola, n. 28, p. 28-31, 2008.

WERMANN, N. Música - Paródia: Uma Ferramenta de Sucesso no Ensino de Química. XII Salão de Iniciação Científica - PUCRS, outubro de 2011. Disponível em <http://ebooks.pucrs.br/edipucrs/anais/seminarioic/20112/5/5/1/1.pdf> Acesso em: 10 set 2017. 